\title{
Low-dielectric-constant polyimide aerogel composite films with low water uptake
}

\author{
Jinyoung Kim, Jinuk Kwon, Myeongsoo Kim, Jeonguk Do, Daero Lee and Haksoo Han
}

A polyimide aerogel (PIA) was used to synthesize low-dielectric-constant polyimide composite films. Unlike silica aerogel (SIA) composites, the PIA films were synthesized using polyimide. The resulting films maintained the original thermal and chemical properties of polyimide, which contribute to their homogeneity. The dielectric constant of the aerogel composite film was decreased to $\sim 2.4$, a value similar to that of a SIA composite film. The increase in dielectric constant as a result of water adsorption exhibited by SIA films was counteracted by the hydrophobicity of the polyimide in the PIA film. The PIA composite film exhibited a $3 \%$ water uptake, compared with a $29 \%$ water uptake in the SIA film, indicating that the polyimide film is the preferred choice in wet conditions. The presence of a uniformly dispersed aerogel, a $1 \%$ thermal decomposition temperature of $589^{\circ} \mathrm{C}$ and a glass transition temperature of $298^{\circ} \mathrm{C}$ for the PIA composite film were confirmed by field emission scanning electron microscopy, thermogravimetric analysis (TGA) and differential scanning calorimetric (DSC) analysis, respectively. The TGA and DSC results demonstrated that the excellent thermal properties of polyimide were maintained in the PIA composite film.

Polymer Journal (2016) 48, 829-834; doi:10.1038/pj.2016.37; published online 30 March 2016

\section{INTRODUCTION}

Microelectronics are currently being developed at an exponential rate because of increasing industrial demands for miniaturization and weight reduction. Devices continuously require development and modification to minimize signal delay and electronic loss. ${ }^{1,2}$ Many studies regarding films with a low dielectric constant and an intermetal dielectric layer are therefore being conducted in view of their applications in a wide range of industries. ${ }^{3-5}$ These films are widely used in microwave striplines, microwave circuits for communications and low capacitance chip connectors. ${ }^{6-10}$ The dielectric constant of a conventional fluorinated polyimide semiconductor is 2.4. ${ }^{11,12}$ However, various porous materials that have previously been evaluated exhibited a lower dielectric constant, such as porous methyl silsesquioxane and porous Poly(aryleneethynylene), both with a dielectric constant of 1.8, and porous SiLK and porous $\mathrm{SiO} 2$, with dielectric constants of 1.5 and 1.1, respectively. ${ }^{8,13,14}$ These materials have only very recently been developed and are limited by their physical properties. Hence, their direct application to existing processes in semiconductor production lines using chemical vapor decomposition or spin-on dielectric methods could prove to be difficult. ${ }^{15}$ Therefore, it is necessary to develop a method for synthesizing low-dielectricconstant materials suitable for application in conventional production lines. In this study, we used a polyimide to synthesize an interlayer with electrical insulation. Polyimide is a material that is widely used in packaging. ${ }^{16,17}$ Its mechanical and thermal properties make it a desirable choice in a variety of applications requiring a lowdielectric-constant material, especially for use in dielectric layers in electronic materials and the field of microelectronics. ${ }^{18-20}$ However, the dielectric constant of homogeneous polyimide is too high to render it an appropriate choice for use in electronic devices. ${ }^{21,22}$ There are two main techniques that may be applied to decrease the dielectric constant. ${ }^{23-25}$ One method involves blending materials, such as poly (arylene-ether), parylene-N/parylene-F and inorganic fillers into polyimide to form C-F bonds, which exhibit low polarity. Another method incorporates air into the material (the dielectric constant of air is 1.0) using porous materials, such as porous poly (arylene-ether) and silica aerogel (SIA) to produce a polyimide matrix. The use of SIA also results in a very low dielectric constant. ${ }^{26,27}$ However, SIA is very sensitive to water because of its hygroscopic properties and is, therefore, easily affected by high levels of moisture. ${ }^{28-31}$ An increase in the dielectric constant of a SIA can be attributed to water uptake. For these reasons, other methods must be considered. In this work, we demonstrate a new method for decreasing the dielectric constant of a polyimide aerogel (PIA) composite film to a value similar to that of a SIA composite film. Unlike the SIA composite film, the PIA does not act as an alien substance in the polyimide film, allowing the film to maintain the excellent thermal and mechanical properties of polyimide. We also analyzed the electric properties of the synthesized PIA composite films.

\section{EXPERIMENTAL PROCEDURE \\ Materials \\ Pyromellitic dianhydride (PMDA) and 4,4'-oxydianiline (ODA), with a purity $>98 \%$, were purchased from Tokyo Chemical Industry (Tokyo, Japan).}


Anhydrous N-methyl-2-pyrrolidinone (NMP) and acetone, with a purity $>99 \%$, were purchased from Duksan Pure Chemicals (Gyeonggi-Do, Korea). The SIAs, with a purity $>99 \%$, were obtained from Cabot (Seoul, Korea). All chemicals were used as received without further purification. A bolt-closure-type autoclave was purchased from Ilshin Autoclave (Daejeon, Korea), allowing for experimental pressure and temperature conditions of up to $11.7 \mathrm{MPa}$ and $250{ }^{\circ} \mathrm{C}$, respectively.

\section{Synthesis of PIA microparticles}

PMDA (10 mM) was dissolved in $20 \mathrm{ml}$ of NMP containing $10 \mathrm{~mm}$ ODA $(2.0024 \mathrm{~g})$ under a nitrogen $\left(\mathrm{N}_{2}\right)$ atmosphere. A PMDA-ODA poly(amic acid) solution was synthesized via the polymerization of PMDA and ODA. The solution was also prepared under a $\mathrm{N}_{2}$ atmosphere and was magnetically stirred at $20^{\circ} \mathrm{C}$ for $24 \mathrm{~h}$. In our previous research, PIA microparticles were synthesized using an autoclave, thus permitting the use of high temperature and pressure conditions. ${ }^{32}$ The poly(amic acid) solution was then transferred to a $30 \mathrm{ml}$ glass bottle and placed in an autoclave. The space between the autoclave and bottle was filled with acetone, and the system was tightly sealed. The autoclave was then placed in an oven and subjected to the following conditions: the temperature was gradually increased from $150{ }^{\circ} \mathrm{C}$ per $30 \mathrm{~min}$ to $200{ }^{\circ} \mathrm{C}$ per $30 \mathrm{~min}$ and then to $250{ }^{\circ} \mathrm{C}$ per $120 \mathrm{~min}$ at a rate of $2{ }^{\circ} \mathrm{C} \mathrm{min}{ }^{-1}$. The autoclave was then opened and the glass bottle was transferred into a vacuum oven at $130{ }^{\circ} \mathrm{C}$ and $1 \mathrm{~atm}$ to remove any remaining NMP and acetone. PIA was then synthesized using PMDA and ODA by the methods described above. After this reaction was complete, the PIA was added to the poly(amic acid) at a particular concentration. The reaction mixture was magnetically stirred at $20^{\circ} \mathrm{C}$ for $24 \mathrm{~h}$. The poly(amic acid)-containing PIA was then spin coated onto glass plates and placed into an oven where the temperature was gradually increased following the pattern of temperature conditions described above. Finally, we obtained polyimide (PI) and PIA composite films (PI-PIA). For comparison, several PI-PIA films containing various PIA concentrations were prepared from 1 to $5 \%$, in $1 \%$ increments, and $10 \%$. SIA composite films (PI-SIA) were also prepared by a similar manner.

\section{Dielectric constants}

To measure the dielectric constants of the materials, the film shown in Figure 1d was cut into $20 \times 20 \mathrm{~mm}^{2}$ and doped on both sides with gold electrodes (thickness $=300 \AA$ ) using a JFC-1100E ion sputter coater (JEOL, Tokyo, Japan) operating at $10 \mathrm{~mA}$ for $3 \mathrm{~min}$ (Figures 1a and b). The average thickness of the coated films was $25 \mu \mathrm{m}$ (Table 1). The doped electrodes were included to provide the necessary level of electrical contact between the films and the capacitance bridge. Subsequently, the films were dried in a drying oven for $24 \mathrm{~h}$ and their dielectric constants were measured using a PM6304 (Fluka, Saint Luois, Missouri, USA) capacitance bridge at $100 \mathrm{kHz}$, at $25^{\circ} \mathrm{C}$ and $0 \%$ humidity (generated using a vacuum pump). The dielectric constants were calculated using the equation provided in Figure 1a.

$$
\varepsilon^{\prime}=\frac{C d}{\varepsilon_{0} A}
$$

where $\mathrm{C}=$ capacitance

$A=$ electrode area

$d=$ film thickness

$\varepsilon^{\prime}=$ dielectric constant of film

a

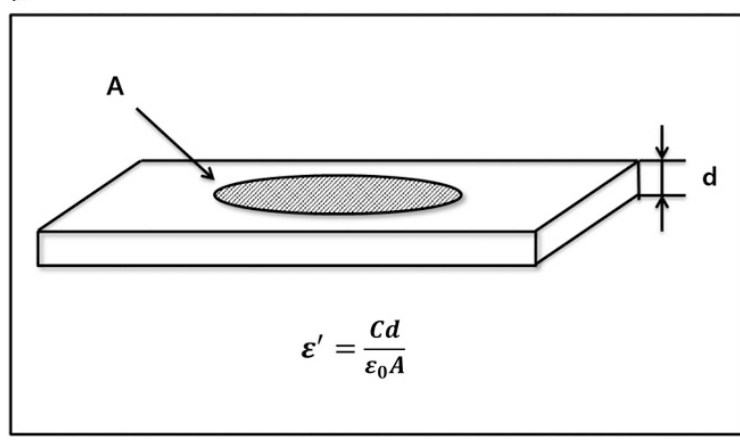

C
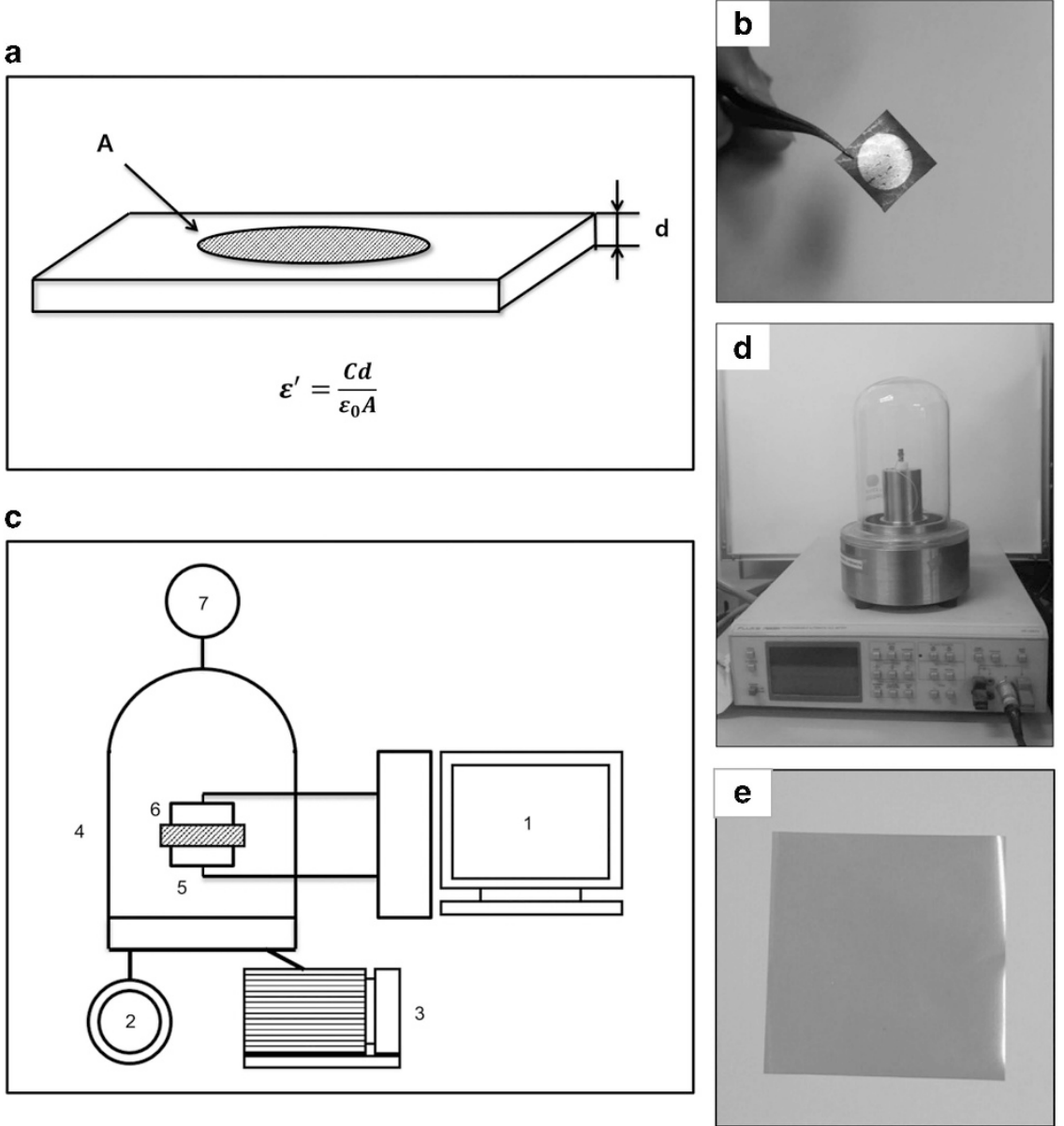

Figure 1 (a) Schematic illustration of a film sample of thickness, $d$, and electrode area, $A$, together with the equation used to measure the dielectric constants. (b) Sample image of a gold-coated film. (c) Schematic illustration of the system used to measure the dielectric constants of the PI-polyimide aerogel (PIA) and PI-silica aerogel (SIA) composite film samples. (d) Image of the system. (e) Image of PI-PIA composite film. A full color version of this figure is available at Polymer Journal online. 
$\varepsilon 0=$ permittivity of free space $\left(=8854 \times 10^{-12}\right)$

These constants were calibrated against a specimen of commercial Kapton (Dupont, dielectric constant $\approx 3.0$ ). A schematic illustration of the device is shown in Figures $1 \mathrm{c}$ and $\mathrm{d}$. To decrease the error in the measured values, the dielectric constant of each sample was measured several times.

\section{Thermogravimetric analysis}

Thermogravimetric analysis analysis was performed using a Q50 instrument (TA Instruments, New Castle, DE, USA). The cured samples were placed in a platinum sample pan and characterized by scanning at temperatures between 30 and $800{ }^{\circ} \mathrm{C}$ at a rate of $10^{\circ} \mathrm{C} \mathrm{min}{ }^{-1}$ under a $\mathrm{N}_{2}$ atmosphere.

\section{Differential scanning calorimetric analysis}

The glass transition temperatures, $\mathrm{Tg}$, of the samples were obtained using a Q10 instrument (TA Instruments) by scanning temperatures between 30 and $375^{\circ} \mathrm{C}$ at a rate of $10^{\circ} \mathrm{C} \mathrm{min}^{-1}$ under a $\mathrm{N}_{2}$ atmosphere.

\section{Water uptake}

The films were placed in an airtight vacuum oven at $120^{\circ} \mathrm{C}$. After $4 \mathrm{~h}$, the vacuum oven was filled with dried $\mathrm{N}_{2}$ gas. The dried films were then removed and weighed. The films were then fully wetted through exposure to air with $90 \%$ humidity for $24 \mathrm{~h}$, which was controlled using a humidity controller that simultaneously verifies and maintains the humidity at a specific rate. The dielectric constants of the wetted samples were then measured, and the films were weighed to determine their water uptake.

Table 1 Water uptakes and dielectric constants of PI, PI-PIA and PI-SIA films in the wet condition

\begin{tabular}{llllllllll}
\hline Item & $\varepsilon^{\prime}{ }_{w}$ & Inc. & Wat. & Thick. & Item & $\varepsilon^{\prime}{ }_{w}$ & Inc. & Wat. & Thick. \\
\hline PIA & & & 3.0 & & SIA & & & 29 & \\
PI-PIA 0\% & 3.96 & 32 & 3.1 & 41 & PI-SIA 0\% & 3.96 & 32 & 3.1 & 41 \\
PI-PIA 1\% & 3.99 & 39 & 3.0 & 25 & PI-SIA 1\% & 3.81 & 37 & 3.5 & 18 \\
PI-PIA 2\% & 4.10 & 51 & 3.2 & 15 & PI-SIA 2\% & 4.02 & 51 & 3.5 & 17 \\
PI-PIA 3\% & 3.90 & 42 & 3.2 & 18 & PI-SIA 3\% & 4.01 & 57 & 3.8 & 23 \\
PI-PIA 4\% & 4.02 & 50 & 3.0 & 17 & PI-SIA 4\% & 4.30 & 70 & 4.2 & 25 \\
PI-PIA 5\% & 3.95 & 55 & 3.2 & 19 & PI-SIA 5\% & 4.81 & 90 & 4.4 & 22 \\
PI-PIA 10\% & 3.82 & 57 & 3.2 & 33 & PI-SIA 10\% & 4.76 & 98 & 5.4 & 27
\end{tabular}

Abbreviations: PIA, polyimide aerogel; SIA, silica aerogel; $\varepsilon_{\mathrm{W}}^{\prime}$, Dielectric constant in the wet condition; Inc., increase in dielectric constant in the wet condition relative to the dielectric constant in the dry condition (\%). Inc. $=\left(\varepsilon_{\mathrm{w}}^{\prime}-\varepsilon_{\mathrm{d}}^{\prime}\right) / \varepsilon_{\mathrm{d}}^{\prime} \times 100 \%$. For example, Inc. for PI-PIA $10 \%$ is calculated as $(3.82-2.44) / 2.44 \times 100 \%=57 \%$. (The dielectric constant in the dry condition is shown in Table 2.); Thick., film thickness ( $\mu \mathrm{m})$; Wat., water uptake weight relative to the $d r$ film weight (\%).

\section{Scanning electron microscopy analysis}

The surface morphology was characterized using a JSM-840A scanning electron microscope (JEOL) operating at $10 \mathrm{kV}$. Before analysis, all samples were sputter coated with a conductive layer of osmium.

\section{Fourier transform infrared spectroscopy}

The Fourier transform infrared spectra of the samples were obtained in the spectral range of $600-4000 \mathrm{~cm}^{-1}$ using an FT/IR-460 Plus spectrometer (Jasco, Tokyo, Japan). The samples were completely dried to avoid any interference caused by any remaining moisture.

\section{Density analysis}

The sample densities were measured using a XB220A gravimetric analyzer (Precisa, Dietikon, Switzerland) at a temperature of $23^{\circ} \mathrm{C}$. American Society for Testing and Materials (ASTM) D792 standard test methods were used to measure the density and specific gravity (relative density) of the plastics based on displacement.

\section{Porosity analysis}

To test the porosity of the sample, the real and apparent densities were measured using AccuPyc II 1340 (Micrometrics, Norcross, GA, USA) and Autopore IV9500 (Micrometrics) respectively. The final porosity (\%) was calculated using $(($ real density - apparent density $) /$ real density $) \times 100 .{ }^{33}$

\section{RESULTS AND DISCUSSION}

\section{Morphological characterization}

Figure 2 shows the porous morphology of the microsphere PIA as observed by field emission scanning electron microscope. Our previous study reported that the size of neat PIA particles ranged from 3.2 to $5.0 \mu \mathrm{m} .{ }^{32}$ Herein, we tested the porosity by measuring real and apparent densities of neat PIA. The real density was found to be $1.503 \mathrm{~g} \mathrm{~cm}^{-3}$ and the apparent density was found to be $0.297 \mathrm{~g} \mathrm{~cm}^{-3}$. Thus, the porosity (\%) of neat PIA was calculated as ((real densityapparent density)/real density) $\times 100$, giving a value of $80 \%$. The image of the cross-section of the PI-PIA films shows that the PIA retained its spherical structure and was well dispersed in the PI composite film (Figure 3a). The enlarged scanning electron microscopy image of the PI-PIA films shows the spatial distribution of PIA. In addition, pure PIA contained multiple pores (Figure 2a), similar to those observed in the PI-PIA composite film (Figures $2 \mathrm{~b}-\mathrm{c}$ ). This observation can be attributed to the internal porous structure of the PIA within the PI film, which results in the decreasing dielectric constant of polyimide composite films. a

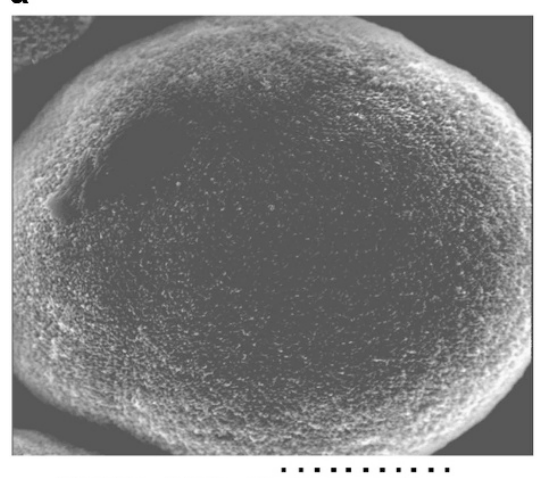

$11550510 \mathrm{KV} \times 7.00 \mathrm{~K} 4.00 \mu \mathrm{m}$ b

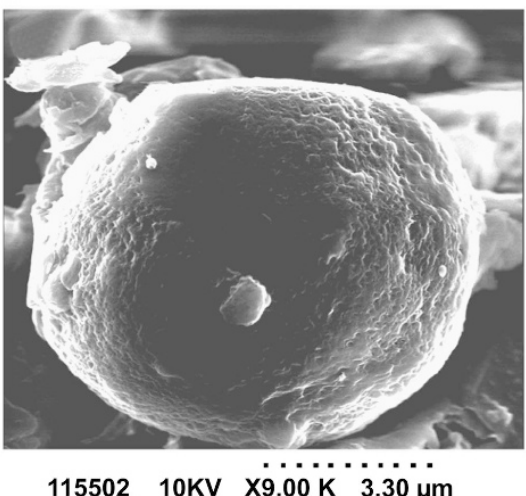

C

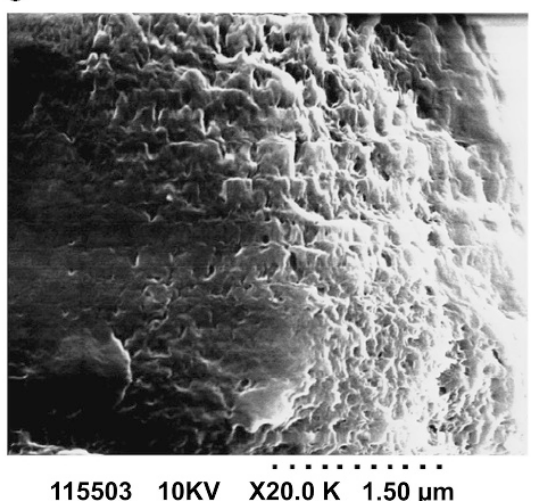

Figure 2 Scanning electron microscopic (SEM) images of (a) a polyimide aerogel (PIA) particle and (b, c) PI-PIA films. SEM images of PI-PIA film samples. The PIA particles were dispersed in the film and retained their spherical shapes. 
a

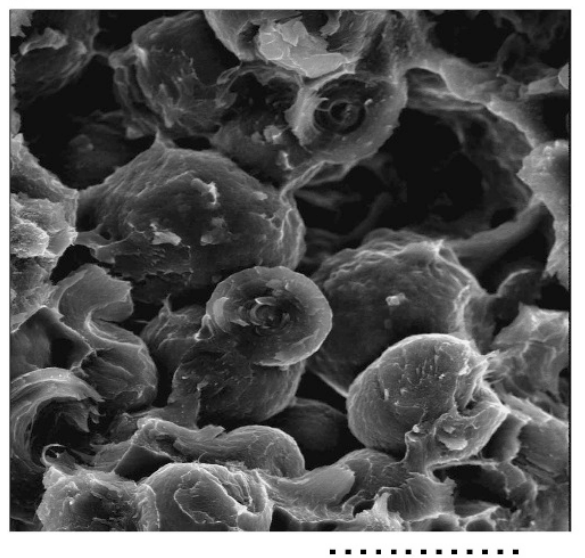

$10 \mathrm{KV} \times 3.50 \mathrm{~K} 8.00 \mu \mathrm{m}$ b

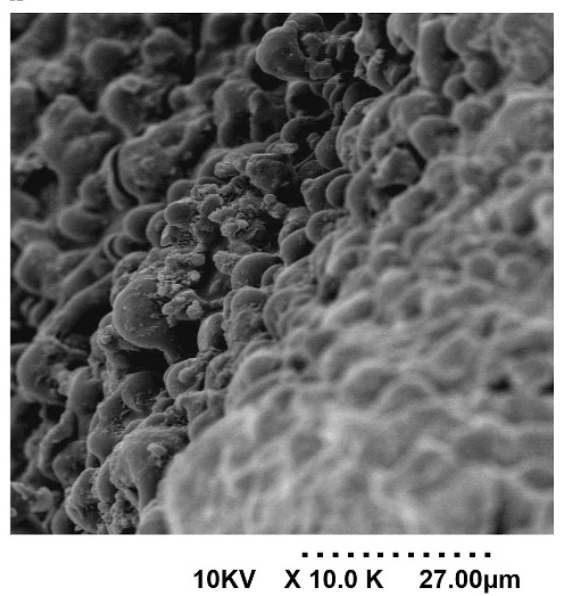

Figure 3 Scanning electron microscopic (SEM) images of PI-polyimide aerogel (PIA) film samples. (a) The PIA particles dispersed in the film and retained their spherical shapes. (b) The cross section of composite film showing PIA particles.

Table 2 Dielectric constants of PI, PI-PIA and PI-SIA films in the dry condition

\begin{tabular}{lclc}
\hline Item & $\varepsilon_{d}^{\prime}$ & Item & $\varepsilon_{d}^{\prime}$ \\
\hline PI-PIA 0\% & 3.00 & PI-SIA 0\% & 3.00 \\
PI-PIA 1\% & 2.88 & PI-SIA 1\% & 2.78 \\
PI-PIA 2\% & 2.71 & PI-SIA 2\% & 2.66 \\
PI-PIA 3\% & 2.75 & PI-SIA 3\% & 2.56 \\
PI-PIA 4\% & 2.68 & PI-SIA 4\% & 2.53 \\
PI-PIA 5\% & 2.55 & PI-SIA 5\% & 2.53 \\
PI-PIA 10\% & 2.44 & PI-SIA 10\% & 2.41
\end{tabular}

Abbreviations: PIA, polyimide aerogel; SIA, silica aerogel; $\varepsilon_{d}^{\prime}$, dielectric constant in the dry condition PIA.

\section{Dielectric constants}

Table 2 gives the dielectric constants of the PI-PIA films under dry conditions, demonstrating a marked variation in the dielectric constant of the films with varying PIA concentration. In particular, the dielectric constant decreased from 3.00 to 2.44 as the PIA content increased, suggesting that PI-PIA is suitable for applications requiring a low dielectric constant. Furthermore, we found that the 10\% PI-PIA composition yielded the lowest dielectric constant. For comparison, similar investigations were conducted using PI-SIA under the experimental conditions described above, the results of which are also given in Table 2. The data contained in Table 2 indicate that the dielectric constants of PI-SIA are comparable to those of the analogous PI-PIA specimens under dry conditions. However, PI-SIA typically exhibited lower dielectric constants attributed to the higher porosity of SIA (90\%) compared with the $80 \%$ porosity of PIA. Water uptake is a major factor that affects the dielectric constant of a material. For this reason, its influence was assessed through the measurement of dielectric constants of the composite film specimens after immersion in water. The 1-10\% PI-PIA samples exhibited a low water uptake of $\sim 3 \%$, whereas the PI-SIA samples absorbed more water $(29 \%)$, as shown in Table 1 . In addition, the water uptake increased rapidly as the SIA content increased, reaching a water absorption proportion of $\sim 5.4 \%$ at a SIA content of $10 \%$, compared with water absorption of $\sim 3.2 \%$ for a PIA content of $10 \%$. The variation in water uptake of PI-PIA according to the PIA contents was barely observable because PI and PIA are synthesized based on the same material, PMDA-ODA, which has a water uptake of $\sim 3.2 \% .^{34}$ Table 1 shows that the dielectric constants of the PI-SIA films rapidly increased as the SIA content was increased, which resulted in the absorption of more water. For the PI-SIA $10 \%$ sample, the dielectric constant of the wet sample was nearly double that of the dry sample, increasing from 2.41 to 4.76 . The latter dielectric constant is higher than that of the wet original polyimide backbone with no filler. In addition, the dielectric constants for all of the PI-SIA samples with concentrations ranging from 1 to $10 \%$ increased considerably in wet conditions. The data given in Table 1 indicate that the increase in the dielectric constant of PI-SIA when wet was as much as $98 \%$ for the $10 \%$ SIA composition. However, in the case of the PI-PIA 10\% sample, the increase was only $\sim 57 \%$. The increased dielectric constants showed no differences for different loadings of PIA in PI-PIA, which is mainly caused by water replacing the air inside the film structure. However, the increasing content of PIA in the PI structure decreased the dielectric constants over a large range compared with PI-SIA. Thus, the dielectric properties of PI-PIA appear to be much more water stable than those of PI-SIA, confirming that PIA is a competitive filler for lowdielectric-constant films.

\section{Thermal properties}

Thermogravimetric and differential scanning calorimetric analyses were conducted to assess the completion of the imidization reaction. The thermogravimetric analysis traces for the 1-10\% PI-PIA compositions were similar to those of the original PI film. Their thermal decomposition temperatures, as determined by thermogravimetric analysis data, were also comparable because of their homogeneity (Figure 4), indicating the completion of the imidization reaction, as shown in Figure 5 . The final weight at $800{ }^{\circ} \mathrm{C}$ strongly depends on the PIA content in PI-PIA, even though the degradation temperature of PI-PIA was not affected by the PIA content. In addition, the Tg values were obtained via differential scanning calorimetric analysis of the PI-PIA composite films and the neat polyimide film (Figure 6), and the glass transition temperatures were determined (Table 3). These results indicate that the PIA compositions did not actually affect the thermal properties of the composite films because of the single material used during synthesis. The variation occurred among composite films of different loadings, which is normal and has been observed under similar reaction conditions. 


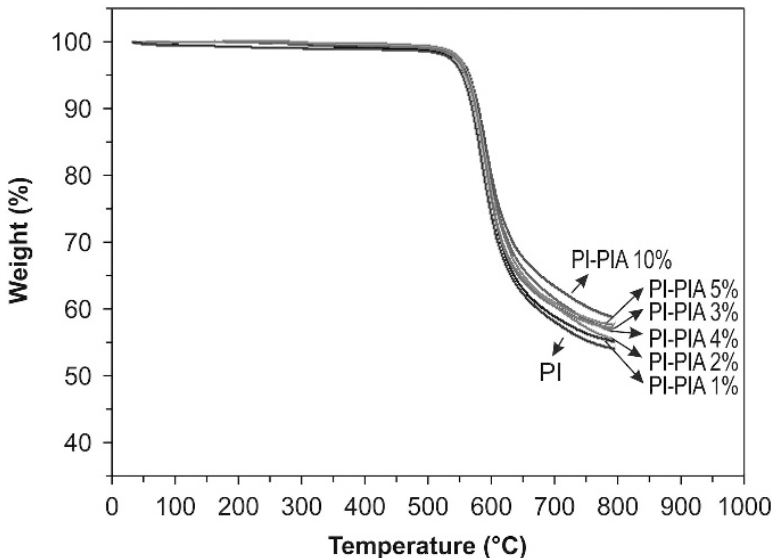

Figure 4 Thermogravimetric analysis (TGA) data for the PI-polyimide aerogel (PIA) film samples. TGA traces for 1-10\% PI-PIA were similar to that of the original PI film, indicating a completed imidization reaction. A full color version of this figure is available at Polymer Journal online.

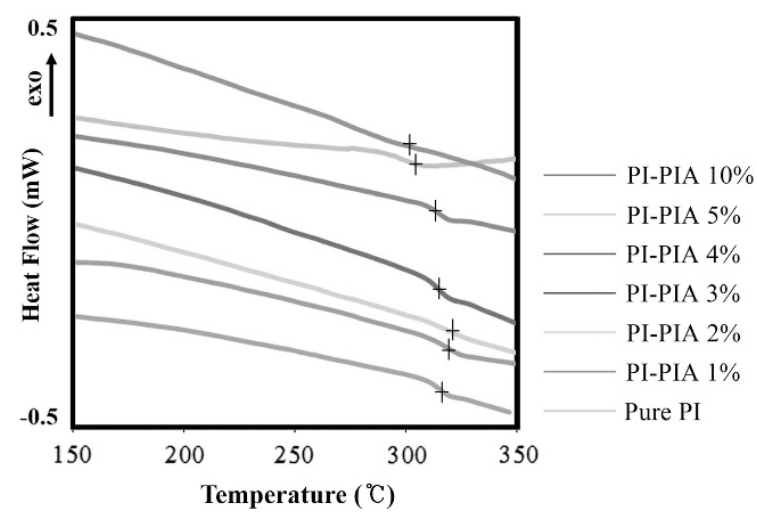

Figure 5 Heat flow with respect to temperature conditions obtained through differential scanning calorimetric (DSC) analysis of the Pl-polyimide aerogel (PIA) samples. The glass transition temperature $(\mathrm{Tg})$ for each sample is indicated. A full color version of this figure is available at Polymer Journal online.

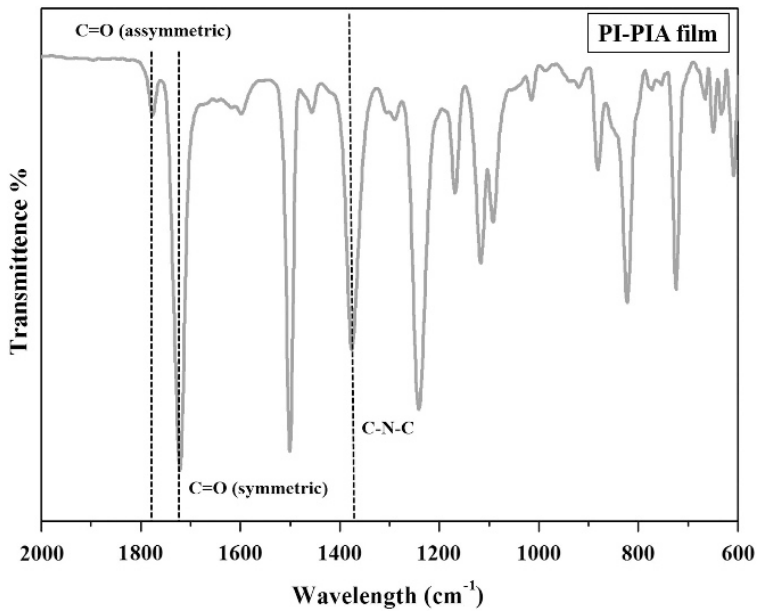

Figure 6 Transmittance spectra for the PI-polyimide aerogel (PIA) films samples, taken from Fourier transform infrared (FT-IR) data. $\mathrm{C}=0$ (symmetric) and $\mathrm{C}=0$ (asymmetric) absorptions are shown at $\sim 1722$ and $1782 \mathrm{~cm}^{-1}$, respectively, while the $\mathrm{C}-\mathrm{N}-\mathrm{C}$ stretching vibration was observed at $\sim 1342 \mathrm{~cm}^{-1}$. A full color version of this figure is available at Polymer Journal online.

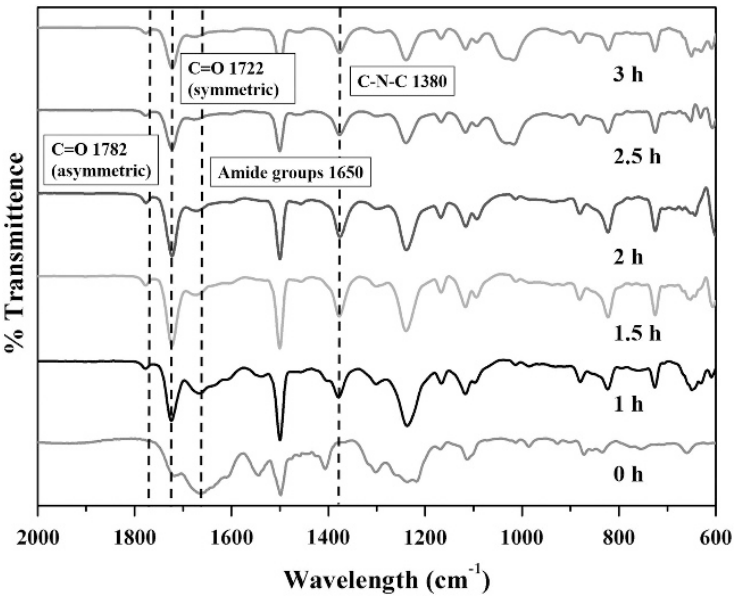

Figure 7 Transmittance spectra of the polyimide film showing the degree of imidization at curing times of $0,0.5,1,1.5,2,2.5$ and $3 \mathrm{~h}$ for a temperature increase from $150^{\circ} \mathrm{C}$ per $30 \mathrm{~min}$ to $200{ }^{\circ} \mathrm{C}$ per $30 \mathrm{~min}$ and then to $250^{\circ} \mathrm{C}$ per $120 \mathrm{~min}$ at a rate of $2^{\circ} \mathrm{C} \mathrm{min}-1$. A full color version of this figure is available at Polymer Journal online.

Table 3 Data of thermal properties analysis by TGA and DSC of PI-PIA and pure PI

\begin{tabular}{lcc}
\hline Item & $\mathrm{Tg}$ & $\mathrm{T}_{1 \%}$ \\
\hline Pure PI & 323 & 589 \\
PI-PIA 1\% & 334 & 581 \\
PI-PIA 2\% & 340 & 578 \\
PI-PIA 3\% & 320 & 590 \\
PI-PIA 4\% & 321 & 585 \\
PI-PIA 5\% & 295 & 591 \\
PI-PIA 10\% & 281 & 588 \\
\hline
\end{tabular}

Abbreviations: PIA, polyimide aerogel; $T_{1 \%}$, thermal decomposition temperature ( $1 \%$ loss; ${ }^{\circ} \mathrm{C}$; $\mathrm{Tg}$, glass transition temperature $\left({ }^{\circ} \mathrm{C}\right)$.

Structure characterization

Fourier transform infrared analysis led to the observation of symmetric and asymmetric absorptions of the imide carbonyl group at $\sim 1722$ and $1782 \mathrm{~cm}^{-1}$, respectively, as shown in Figure 6. Furthermore, the $\mathrm{C}-\mathrm{N}-\mathrm{C}$ stretching vibration of the imide ring was observed at $\sim 1342 \mathrm{~cm}^{-1} .18$ These results confirm that the specimens were sufficiently imidized.

Degree of imidization

To determine the degree of imidization, polyimide films were subjected to different curing times using the original temperature condition profile for imidization described in the Materials and methods section as follows: the temperature was gradually increased from $150{ }^{\circ} \mathrm{C}$ per $30 \mathrm{~min}$ to $200^{\circ} \mathrm{C}$ per $30 \mathrm{~min}$ and then to $250{ }^{\circ} \mathrm{C}$ per $120 \mathrm{~min}$ at a rate of $2^{\circ} \mathrm{C} \mathrm{min}{ }^{-1}$, for $0,0.5,1,1.5,2,2.5$ and $3 \mathrm{~h}$. The absorbance peaks show the carbonyl vibrations of the amide groups in poly (amic acid)s near $1650 \mathrm{~cm}^{-1}$, which decreases with increasing curing time. Increasing trends were observed at 1722 and $1782 \mathrm{~cm}^{-1}$, indicating the presence of imide carbonyl groups. However, $\mathrm{C}-\mathrm{N}-\mathrm{C}$ bonding occurring at $1380 \mathrm{~cm}^{-1}$ gradually increased as the curing time increased (Figure 7). Thus, complete imidization was observed on curing. 


\section{CONCLUSIONS}

Water uptake is a major concern when applying SIA as a filler in lowdielectric-constant materials. In this work, polyimide films were used to assess the water uptake of silica and PIAs. In our previous research, PIAs were shown to be highly porous materials. To demonstrate the applicability of this material to low-dielectric constant films, we designed PIA films with a low dielectric constant. The PIA composite films exhibited the desired properties, suggesting that PIAs could potentially replace SIAs for use in low-dielectric-constant films. Our experiments indicated that the water uptake of the composite films increased rapidly with increasing SIA content, whereas the PIA content had little influence on the water uptake of the composite films. Although the dielectric tendencies of the dry composite films containing SIA and PIA were similar, the dielectric constants of the films containing PIA did not increase nearly as rapidly as those containing SIA under wet conditions. The PIA composite film also exhibited high decomposition and glass transition temperatures of 589 and $298^{\circ} \mathrm{C}$, respectively. These findings indicate that PIA is a superior choice for use as a filler in the fabrication of low-dielectric-constant films.

\section{CONFLICT OF INTEREST}

The authors declare no conflict of interest.

\section{ACKNOWLEDGEMENTS}

This work was supported by the LG Display Academic Industrial Cooperation Program, GTC and the KIST Institutional Program (Project No. 2E25420-15129).

1 Wang, W., Grozea, D., Kim, A., Perovic, D. D. \& Ozin, G. A. Vacuum-assisted aerosol deposition of a low-dielectric-constant periodic mesoporous organosilica film. Adv. Mater. 22, 99-102 (2010).

2 Homma, T. Low Dielectric Constant Materials and Methods for Interlayer Dielectric Films in Ultralarge-Scale Integrated Circuit Multilevel Interconnections. Mater. Sci. Eng. R Rep. 23 (6): 243-285 (1998).

3 Maex, K., Baklanov, M. R., Shamiryan, D., Lacopi, F., Brongersma, S. H. \& Yanovitskaya, Z. S. Low dielectric constant materials for microelectronics. J. Appl. Phys 93, 8793 (2003).

4 Cole, M. W., Nothwang, W. D., Hubbard, C., Ngo, E. \& Ervin, M. Low dielectric loss and enhanced tunability of $\mathrm{BaO}$. 6SrO. 4TiO3 based thin films via material compositional design and optimized film processing methods. J. Appl. Phys. 93, 9218 (2003).

5 Leu, C., Chang, Y. \& Wei, K. Polyimide-side-chain tethered polyhedral oligomeric silsesquioxane nanocomposites for low-dielectric film applications. Chem. Mater. 15, 3721-3727 (2003).

6 Yu, W., Fu, J., Dong, X., Chen, L. \& Shi, L. A graphene hybrid material functionalized with POSS: Synthesis and applications in low-dielectric epoxy composites. Compos. Sci. Technol. 92, 112-119 (2014).

7 Wang, X., Xing, W., Zhang, P., Song, L., Yang, H. \& Hu, Y. Covalent functionalization of graphene with organosilane and its use as a reinforcement in epoxy composites. Compos. Sci. Technol. 72, 737-743 (2012).

8 Volksen, W., Miller, R. D. \& Dubois, G. Low dielectric constant materials. Chem. Rev. 110, 56-110 (2010).
9 Sebastian, M. T. \& Jantunen, H. Low loss dielectric materials for LTCC applications: a review. Int. Mater. Rev. 53, 57-90 (2008).

10 Lee, B., Park, Y.-H., Hwang, Y.-T., Oh, W., Yoon, J. \& Ree, M. Ultralow-k nanoporous organosilicate dielectric films imprinted with dendritic spheres. Nat. Mater. 4, 147-150 (2005).

11 Ho, P. S., Leu, J. \& Lee, W. W. Low Dielectric Constant Materials for IC Applications, Vol. 9 (Springer Science \& Business Media, New York, NY, USA, 2003).

12 Yang, H., Choi, S., Hyun, S. \& Park, C. Ambient-dried SiO2 aerogel thin films and their dielectric application. Thin Solid Films 348, 69-73 (1999).

13 Jo, M., Park, H., Kim, D., Hyun, S. \& Choi, S. Application of SiO2 aerogel film with low dielectric constant to intermetal dielectrics. Thin Solid Films 308, 490 (1997).

14 Morley, K. S., Licence, P., Marr, P. C., Hyde, J. R., Brown, P. D., Mokaya, R., Xia, Y. \& Howdle, S. M. Supercritical fluids: A route to palladium-aerogel nanocomposites. J. Mater. Chem. 14, 1212 (2004).

15 Quirk, M. \& Serda, J. Semiconductor Manufacturing Technology (Prentice Hall, Upper Saddle River, NJ, USA, 2001).

16 Jensen, R. J., Cummings, J. P. \& Vora, H. A. Copper/polyimide materials system for high performance packaging. IEEE Trans. Comp. Hybrids Manuf. Technol. 7, 384-393 (1984)

17 Takasago, H., Adachi, K. \& Takada, M. A copper/polyimide metal-base packaging technology. J. Electron. Mater. 18, 319-326 (1989).

18 Tyan, H., Liu, Y. \& Wei, K. Thermally and mechanically enhanced clay/polyimide nanocomposite via reactive organoclay. Chem. Mater. 11, 1942-1947 (1999).

19 Agag, T., Koga, T. \& Takeichi, T. Studies on thermal and mechanical properties of polyimide-clay nanocomposites. Polymer 42, 3399-3408 (2001).

20 Huang, J., He, C., Xiao, Y., Mya, K. Y., Dai, J. \& Siow, Y. P. Polyimide/POSS nanocomposites: interfacial interaction, thermal properties and mechanical properties. Polymer 44, 4491-4499 (2003).

21 Ghosh, M. Polyimides: Fundamentals and Applications (CRC Press, Marcel Dekker, Inc., Florida, USA, 1996).

22 Wilson, D., Stenzenberger, H. D. \& Hergenrother, P. M. Polyimides (Springer, Blackie \& Son Ltd., Glasgow, Scotland, 1990).

23 Aram, E. \& Mehdipour-Ataei, S. Preparation of thermally stable, low dielectric constant, pyridine-based polyimide and related nanofoams. J. Appl. Polym. Sci. 128, 4387-4394 (2013)

24 Deligöz, H., Özgümüş, S., Yalçınyuva, T., Yıldırım, S., Deǧer, D. \& Ulutaş, K. A novel cross-linked polyimide film: synthesis and dielectric properties. Polymer 46, 3720-3729 (2005).

25 Lin, T., Jianqing, Z., Fang, Z. \& Shumei, L. Progress in synthesis of low dielectric constant polyimide. Petrochem. Technol. 7, 744-749 (2008).

26 Ayers, M. R. \& Hunt, A. J. Molecular oxygen sensors based on photoluminescent silica aerogels. J. Non-Cryst. Solids 225, 343-347 (1998).

27 Pryde, C. A. IR studies of polyimides. I. Effects of chemical and physical changes during cure. J. Polym. Sci. A Polym. Chem. 27, 711-724 (1989).

28 Miner, M. R., Hosticka, B. \& Norris, P. M. The effects of ambient humidity on the mechanical properties and surface chemistry of hygroscopic silica aerogel. J. Non-Cryst. Solids 350, 285-289 (2004).

29 Tsai, C.-H., Yang, F.-L., Chang, C.-H. \& Chen-Yang, Y. W. Microwave-assisted synthesis of silica aerogel supported pt nanoparticles for self-humidifying proton exchange membrane fuel cell. Int. J. Hydrogen Energy 37, 7669-7676 (2012).

30 Guo, H., Meador, M. A. B., McCorkle, L., Quade, D. J., Guo, J., Hamilton, B., Cakmak, M. \& Sprowl, G. Polyimide aerogels cross-linked through amine functionalized polyoligomeric silsesquioxane. ACS Appl. Mater. Interfaces 3, 546-552 (2011).

31 Yim, T., Kim, S. \& Yoo, K. Fabrication and thermophysical characterization of nanoporous silica-polyurethane hybrid aerogel by Sol-Gel processing and supercritical solvent drying technique. Korean J. Chem. Eng. 19, 159-166 (2002).

32 Kwon, J., Kim, J., Yoo, T., Park, D. \& Han, H. Preparation and characterization of spherical polyimide aerogel microparticles. Macromol. Mater. Eng. 299, 1025 (2014).

33 Kwon, J., Kim, J., Park, D. \& Han, H. A novel synthesis method for an open-cell microsponge polyimide for heat insulation. Polymer 56, 68-72 (2015).

34 Lee, C., Shul, Y. \& Han, H. Dielectric properties of oxydianiline-based polyimide thinfilms according to the water uptake. J. Polym. Sci. B Polym. Phys. 40, 2190-2198 (2002) 